\title{
Development and evaluation of two web- based interventions for the promotion of physical activity in older adults: study protocol for a community-based controlled intervention trial
}

Saskia Muellmann ${ }^{1}$, Inna Bragina², Claudia Voelcker-Rehage ${ }^{2}$, Eric Rost ${ }^{3}$, Sonia Lippke ${ }^{3}$, Jochen Meyer ${ }^{4}$, Jochen Schnauber ${ }^{4}$, Merlin Wasmann ${ }^{4}$, Merle Toborg ${ }^{5}$, Frauke Koppelin ${ }^{5}$, Tilman Brand ${ }^{1}$, Hajo Zeeb ${ }^{1,6}$ and Claudia R. Pischke ${ }^{1 *}$

\begin{abstract}
Background: Regular physical activity (PA) is a key contributor to healthy ageing. However, despite known health benefits, only one third of older adults in Germany reach the PA levels recommended for persons aged 65 years and above by the World Health Organization. The aim of the current study is to evaluate the effectiveness of two web-based interventions for the initiation and maintenance of regular PA (i.e., intervention groups 1 and 2) compared to a delayed intervention control group of older adults aged 65 to 75 years.
\end{abstract}

Methods/Design: Study participants will be randomly assigned to one of three study arms in five communities in the Bremen-Oldenburg metropolitan region: a) Participants in the first arm will receive access to a web-based intervention for 10 weeks allowing them to track their weekly PA (subjective self-monitoring, intervention group 1); b) participants in the second arm will receive access to the web-based intervention for 10 weeks and, in addition, track PA using Fitbit Zips (objective self-monitoring, intervention group 2); c) participants in the delayed intervention control group will receive access to the intervention implemented in the first study arm after completion of the 12-week follow-up in the other two groups within each community. In addition, weekly group meetings in the communities will be offered to study participants in the intervention groups providing the opportunity to address questions related to the use of the website and to practice PA in groups (e.g., neighborhood walks, strength and balance exercises). To evaluate short-term effects of the intervention on physical and psychological health, PA, physical fitness, and cognitive and psychological variables will be assessed at baseline and 12-week follow-up.

Discussion: This study will provide answers regarding acceptance and effectiveness of web-based interventions promoting uptake and maintenance of regular PA in persons aged 65-75 years. Study findings will contribute to a growing body of evidence in Germany concerning the role of community-based interventions for the promotion of PA and healthy ageing in older adults.

Trial registration: German Clinical Trials Register DRKS00010052 (Date of registration 07-11-2016).

Keywords: Physical activity, Older adults, eHealth, Intervention, Physical activity promotion, Primary prevention, Healthy ageing

\footnotetext{
* Correspondence: pischke@leibniz-bips.de

${ }^{1}$ Leibniz Institute for Prevention Research and Epidemiology - BIPS,

Achterstrasse 30, 28359 Bremen, Germany

Full list of author information is available at the end of the article
} 


\section{Background}

Regular physical activity (PA) is associated with improvements in physical, psychological, cognitive, and functional health [1-4]. The World Health Organization (WHO) and the American College of Sports Medicine (ACSM) recommend a weekly moderate exercise time of $150 \mathrm{~min}$ for adults aged 60 years and above. Moreover, it is recommended that older adults engage in flexibility and strength training at least two times per week $[5,6]$. The percentages of older adults (aged 60 years and above) meeting the recommendation for moderate exercise time range from $2 \%$ to $83 \%$, depending on the study [7]. In Germany, only $18 \%$ of adults between the ages of 60 and 69 years and $14 \%$ of adults between the ages of 70 and 79 years meet the current recommendations for PA [8].

Physical limitations due to health conditions or agerelated restrictions, as well as a lack of age-appropriate PA programs and information regarding access to such programs, are barriers to program participation and to reaching PA recommendations in this population [9]. In contrast, high levels of personal motivation to stay physically and mentally active, as well as having access to affordable and appropriate exercise options, are perceived as facilitators for reaching and maintaining PA recommendations by older adults [9].

Interventions providing information on PA as print versions $[10,11]$ or face-to-face [12] have a long tradition and previous studies suggests that these interventions are effective in promoting PA in older adults. The increased use of the internet and mobile technologies in recent years may open up new opportunities for promoting PA in this population $[13,14]$. In Germany, $50 \%$ of adults aged 60 years and above already use the internet regularly [15], 17\% of adults aged 65 years and above use smartphones [16], and this trend is increasing. Hence, eHealth interventions (i.e., measures to promote health using information and communication technologies [17]), appear promising for reaching this population and for providing individualized PA programs. To date, a variety of studies (predominantly conducted outside of Germany) investigated the role of eHealth interventions to promote PA in older adults suggesting that participation in eHealth interventions leads to increased levels of PA [18-21].

Because a large body of evidence indicates that tailoring of intervention materials and messages to participants' characteristics, such as gender, PA level at study entry, and readiness to engage in $\mathrm{PA}$, is associated with greater success in achieving PA goals in the long-term [20, 2226], intervention materials employed in the majority of the interventions in the above cited studies used tailoring. However, although a wide range of PA interventions is available in Germany [27], only few are tailored to characteristics and needs of older adults or readiness to engage in PA and the majority of studies investigating effects of PA interventions in this population demonstrated rather small behavioral changes [25]. Furthermore, the effects of self-monitoring of PA behavior via web-based diaries, logs or tracking devices have, thus far, not been systematically investigated in older populations in Germany.

Therefore, the main aim of the current study is to compare the effectiveness of two different web-based interventions (encouraging subjective vs. subjective and objective PA self-monitoring) among older adults living in five communities in the Bremen-Oldenburg metropolitan region to a delayed intervention control group. Recommendations regarding PA and intervention materials provided to participants of both web-based interventions will be tailored to gender, PA-level, and stage of readiness to engage in the interventions assessed at baseline. The study is embedded in the larger Physical Activity and Health Equity: Primary Prevention for Healthy Ageing (AEQUIPA) research network which is funded by the Federal Ministry of Education and Research (BMBF).

\section{Methods}

Aims of the overall AEQUIPA project and network

The network conducts theory-based and participatory empirical research in the Northwestern part of Germany (http://www.aequipa.de/en/home.html, [28]). It aims to develop, implement, and evaluate PA interventions for the primary prevention of chronic diseases in persons aged 65 years and above. With five subprojects, AEQUIPA's goal is to strengthen the evidence base for preventive PA in the context of healthy ageing and to gain new insights into environmental, social-contextual, and individual factors influencing PA in persons aged 65 years and above. This study is one of five subprojects of the entire network.

\section{Study aims}

The following main research question will be examined in this study:

- Is a web-based intervention with subjective and objective PA monitoring more effective for the promotion of PA among older adults than a webbased intervention with subjective PA monitoring only compared to a delayed intervention control group?

Secondary research questions of the study are the following:

- Do participants' characteristics (e.g., age, gender, motivational stage) influence intervention attendance and PA behavior? 
- Is participation in the web-based interventions associated with improvements in secondary outcomes, such as well-being, quality of life, fear of falling, physical and cognitive functioning?

An additional objective of the study is to improve our understanding of how web-based interventions and technologies for PA tracking ought to be designed to be usable for the target group and which features ought to be included from the user's point of view.

\section{Selection of communities for the study}

Preceding recruitment for this study and as part of another subproject of the AEQUIPA network (RTC project, see [29]), a cross-sectional community readiness assessment (CRA) regarding the uptake and/or implementation of PA interventions in older adults (6575 years) was conducted in a sample of municipalities within the Bremen-Oldenburg metropolitan region. The CRA was based on a structured interview administered to key informants, such as representatives from local public authorities, senior citizen organizations or sports clubs in each of the selected communities [29]. Municipalities were selected for inclusion if they already had a comparably high proportion of older adults or if they expected a high increase in the proportion of older adults living in the region over the next decade. Overall, 23 municipalities (12 rural, 11 urban) were included in the assessment. The five communities with the lowest levels of community readiness were selected for the implementation of PA interventions (three urban communities: Burglesum, Bremen; Vahr, Bremen; Obervieland, Bremen; two rural communities: Osterholz-Scharmbeck, Lower Saxony; Achim, Lower Saxony).

\section{Participants and procedures}

Names and addresses of men and women between the ages of 65 and 75 years residing in these five communities of the metropolitan region of Bremen-Oldenburg will be drawn from the records of the residents' registration office. Subsequently, persons will be invited to participate in the study via mail. The study will also be publicized in local newspaper articles, in senior organizations, and as part of capacity building activities of the RTC project. Eligibility for study participation will be determined in telephone interviews with trained study nurses following the inclusion and exclusion criteria outlined below.

\section{Inclusion and exclusion criteria}

Residents of the five communities will be eligible for study participation if they are between the ages of 65 and 75 years, if they are able to live independently (i.e., in own apartment or room without assisted living, no regular home nursing), and if they provide an informed consent to participate in the study. Further criteria for inclusion in the study are basic knowledge of German, the ability to walk without a walking aid, and to participate in study assessments and weekly group meetings without external support. Also, internet access at home or at family members' or friends' houses is a precondition for participation. Participants will be excluded from the study if they have planned a vacation for more than one month during the intervention period, display cognitive impairment (Mini-Mental-Score $\leq 27$ ) or other permanent impairments (e.g., stroke, neurological diseases, such as Parkinson's) or if there are any medical contraindications regarding program participation.

After successful screening for study eligibility, study participants will be assigned to one of three study arms by the study nurses: a) a web-based intervention with subjective PA self-monitoring (intervention group 1), b) a web-based intervention with subjective and objective PA self-monitoring (intervention group 2) or c) a delayed intervention control group (waitlisted control group) receiving the intervention of intervention group 1 after completion of the 12-week follow-up (see Fig. 1 for the study design). Each intervention condition will be randomly assigned to certain weeks of baseline assessment. Participants will be free to choose from available time slots during a phone call with a study nurse, but only after their decision will they be informed about which intervention condition was assigned to this particular week.

\section{Measures}

Participants will be invited to the study center to complete baseline (T0) and follow-up assessments (T1). At the study center, participants will undergo different anthropometric, physical, motor and cognitive tests, as well as an assessment of motivational stages to engage in PA. Cardiovascular fitness will be assessed using the 2min step test [30]. Functional status and physical performance will be measured employing the Short Physical Performance Battery (SPPB) which includes balance, gait speed, and chair raising tests [31]. Moreover, postural control under dynamic conditions [32], strength of the upper extremities [33], hand grip strength [34], height, weight, and body fat will be assessed using stadiometers and bioimpedance scales. Cognitive dysfunction [35], memory (Verbal Learning and Memory Test (VLMT), [36]), and attention and inhibition (Simon Task, [37]) will be assessed in cognitive tests. In addition, working memory updating and inhibition (Random Number Generation Test (RNGT), [38]), and postural control under static conditions (measure of tandem stand by use of iPad, software: Sensor Data, Wavefront Labs, [39]) will be assessed under single- and dual-task conditions. 


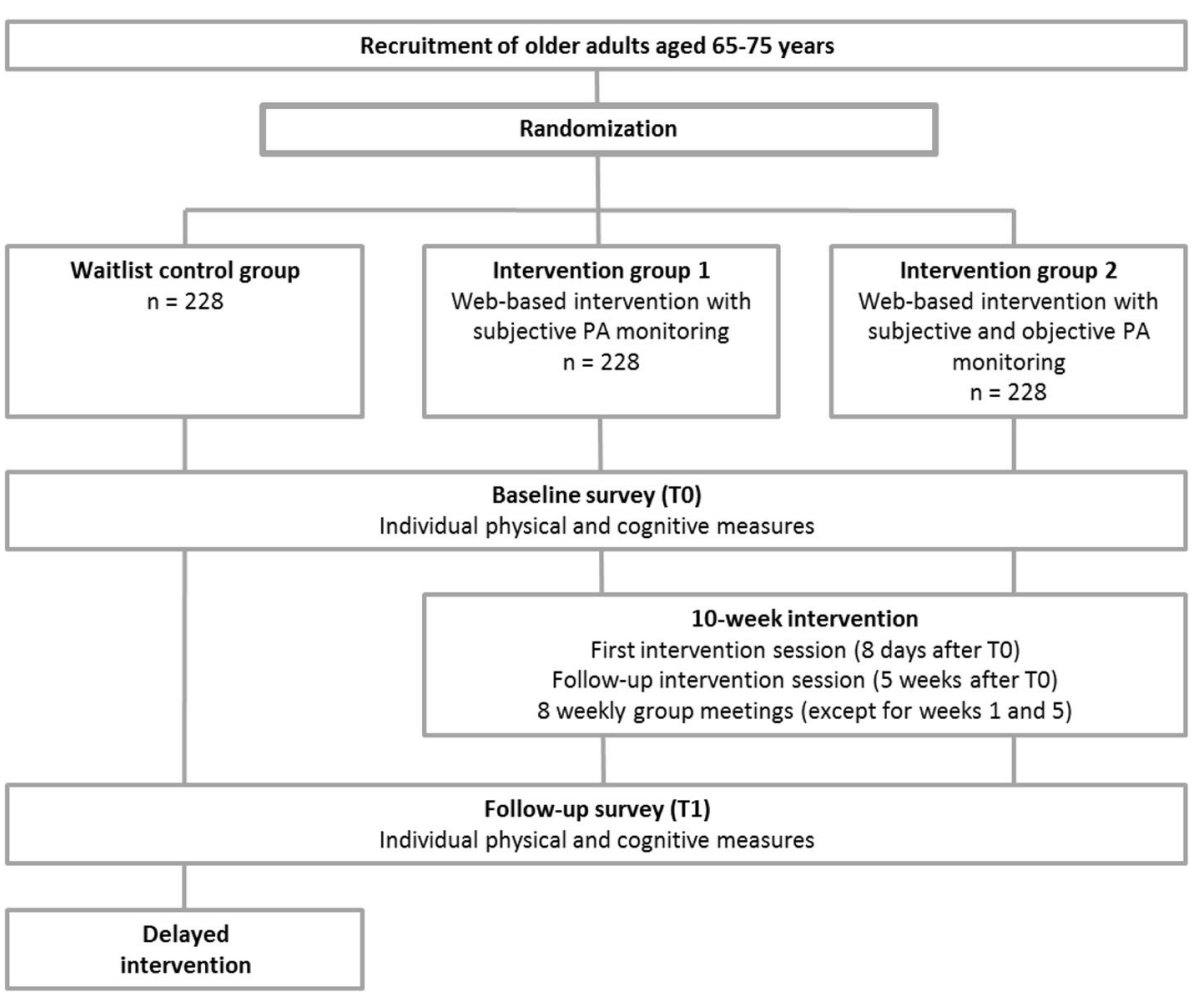

Fig. 1 Study Design

Motivational stages regarding PA will be measured via a validated algorithm [40, 41].

After both assessments, all participants will receive an accelerometer (ActiGraph GT3x+) to objectively measure PA and a self-administered questionnaire. Participants will be instructed to wear the accelerometer on the right hip and during the day for seven days following baseline and follow-up assessments. The self-administered questionnaire will contain validated instruments and self-generated items assessing levels of PA, perceived physical environment, social support, health behavior, quality of life, and previous experience with using technology (for further detail on the instruments included in the questionnaire, see Table 1). Sociodemographic information will include age, gender, migration background, education, employment, and household income. In addition, participants of intervention groups 1 and 2 will fill out a self-administered questionnaire at the follow-up comprised of self-generated items regarding use and acceptance of the website, attendance of the offered group sessions, and overall satisfaction with the interventions.

\section{Interventions}

Two web-based interventions promoting self-monitoring of PA will be developed. Both will be based on selfregulation theory $[42,43]$ and on principles of behavior change (e.g., shaping knowledge, feedback and monitoring, goals and planning, social support, comparison of behavior, rewards, [44]). Participants in the intervention groups will receive brochures with PA recommendations including exercises to improve balance (two times per week), strength (on two or more nonconsecutive days per week involving major muscle groups), and endurance (for at least $150 \mathrm{~min}$ with moderate intensity or at least $75 \mathrm{~min}$ with vigorous intensity each week in bouts of $10 \mathrm{~min}$, or an appropriate combination of both types of activities), according to the recommendations of the WHO and the ACSM. Depending on PA-level assessed at baseline and gender, participants will be provided with different brochures outlining exercises for different levels of difficulty and displaying pictures of male vs. female older adults modeling the exercises.

In the first intervention arm (intervention group 1), participants will receive access to a web-based PA diary and will be encouraged to track their behavior over a 10 -week period. Participants in the second intervention arm (intervention group 2) will additionally receive Fitbit Zips (Fitbit, San Francisco, USA) to objectively track PA; data of the Fitbit Zips will be synchronized with the website following regular time intervals. The website will provide weekly feedback on whether PA goals (WHO recommendations for moderate exercise time, flexibility and strength training) are reached (and goal-specific rewards), and will provide opportunities to 
Table 1 Measures in the self-administered study questionnaire

\begin{tabular}{|c|c|}
\hline Outcome measure & Instrument/scale \\
\hline \multicolumn{2}{|l|}{ Physical activity } \\
\hline Physical activity & International Physical Activity Questionnaire (IPAQ) [49] \\
\hline Intention to engage in physical activity & Health Action Process Approach (HAPA), intention $[40,41]$ \\
\hline Self-efficacy regarding physical activity & HAPA, self-efficacy $[40,41]$ \\
\hline Planning for physical activity & HAPA, planning $[40,41]$ \\
\hline Physical self description & Physical self-description (PSDQ) [50] \\
\hline \multicolumn{2}{|l|}{ Physical environment } \\
\hline Physical activity and neighborhood environment & $\begin{array}{l}\text { International Physical Activity Questionnaire Environmental } \\
\text { module (IPAQ-E) [51] }\end{array}$ \\
\hline \multicolumn{2}{|l|}{ Social support, social activities } \\
\hline Social support for engaging in physical activity & Social support and exercise survey (modified, $[40,41]$ ) \\
\hline Social networks & Self-generated items \\
\hline Social activities & Florida Cognitive Activities Scale (modified, [52, 53]) \\
\hline \multicolumn{2}{|l|}{ Health behavior } \\
\hline Subjective age & Self-generated item \\
\hline Health-related quality of life & Short-Form (SF)-12, only 1 item [54] \\
\hline Objective health & Diseases and medication use (modified, [55]) \\
\hline Risk perception & Berlin Risk Appraisal and Health Motivation Study (BRAHMS) [56] \\
\hline Falls & Elderly Fall Screening Test (EFST) (modified, [57]) \\
\hline Fear of falling & Geriatric Fear of Falling Measurement (GFFM) [58] \\
\hline Diet & Food Frequency Questionnaire [59] \\
\hline Alcohol consumption & $\begin{array}{l}\text { Alcohol Use Disorders Identification Test Short Version } \\
\text { (AUDIT-C) [60] }\end{array}$ \\
\hline Smoking behavior & Smoking Behavior Questionnaire [61] \\
\hline $\begin{array}{l}\text { Stage assessment of smoking behavior, alcohol consumption, } \\
\text { fruits and vegetable consumption }\end{array}$ & Stage assessment $[40,41]$ \\
\hline \multicolumn{2}{|l|}{ Quality of life and well-being } \\
\hline Quality of life & Satisfaction with Life Scale (SWLS) [62] \\
\hline Emotional well-being & Self-generated items \\
\hline Depression & Centers for Epidemiologic Studies Depression Scale (CES-D) [63] \\
\hline Personality & NEO Five Factor Inventory (NEO-FFI) [64] \\
\hline \multicolumn{2}{|l|}{ Previous experiences with technology } \\
\hline Use of computers/smartphones/applications & Self-generated items \\
\hline Technology commitment & Technology Commitment Scale [65] \\
\hline \multicolumn{2}{|l|}{ Use, acceptance, and satisfaction with interventions } \\
\hline $\begin{array}{l}\text { Use and acceptance of various components of the website, } \\
\text { attendance of the offered group sessions, and overall satisfaction } \\
\text { with the interventions }\end{array}$ & Self-generated items \\
\hline
\end{tabular}

network with other intervention participants via an invite friends function and a forum. In addition to the web-based interventions, participants will be offered weekly group meetings in their communities led by trained research assistants. During these 90-min meetings, participants can resolve technical problems with the website, receive health education regarding healthy ageing, and practice PA in groups. All intervention materials (e.g., PA recommendations and instructions) will be tailored to participants' age, gender, motivation to engage in PA, and PA-level assessed at baseline.

One week after the baseline assessment, the intervention will be introduced to participants of intervention groups 1 and 2 separately in group sessions with a maximum of 24 participants. Five weeks after the start of the 
intervention, a second group meeting will be held to ensure the proper use of the website and the Fitbit Zips in the two intervention groups. After completion of the follow-up assessment, persons in the delayed intervention control group will receive access to the web-based intervention of intervention group 1. However, no weekly group meetings will be offered to participants in this study arm.

\section{Qualitative research informing the design of the interventions}

All assessment and intervention materials will be pilot tested with seniors in a different region of Germany than the intervention and assessment sites to prevent spill-over effects. A four-week pilot intervention and a focus group interview will be conducted. During this pilot, participants will be asked whether they are satisfied with the support received during the intervention period and with the comprehensibility and difficulty of the exercise brochures. Focus groups with participants who receive Fitbit Zips to objectively track PA in the second intervention arm will be conducted to assess the usability of the Fitbit Zips. Adaptations to all intervention materials and the website will be made based on the results of these pilot tests.

\section{Analytic strategy \\ Quantitative analysis, sample size}

Hierarchical linear regression models will be used to analyze the intervention effects. Due to the week-wise randomization scheme, recruitment week will be included as a clustering variable. Change over time in objectively measured PA will serve as the primary outcome variable. Change over time will be calculated by subtracting the baseline value from the follow-up value $\left(\mathrm{PA}_{\mathrm{T} 1}-\mathrm{PA}_{\mathrm{T} 0}\right)$. To assess the intervention effects, two dummy variables for intervention groups 1 and 2 will be added contrasting the change over time in PA in each intervention arm with the changes in the delayed intervention control group. Expecting small to moderate intervention effects [45], we calculated the sample size assuming a standardized mean difference of 0.33 in change over time between the intervention groups and the delayed intervention control group. Further, assuming ten clusters (recruitment weeks) per study arm and an intraclass correlation of $0.01,190$ participants per study arm will be necessary for the analysis with $\alpha=0.05$ (two-sided test) and $\beta=0.20$. Expecting a loss to follow-up of $20 \%$, we aim for a sample size of $n=684$ at baseline.

Changes in cardiovascular fitness, physical performance, body fat, cognitive dysfunction, fear of falling, and quality of life will be analyzed as secondary outcomes. Several variables will be included as potential confounders, such as baseline PA-level, age, gender, education, motivational stage, and other health behaviors. In additional analyses, the moderating influence of gender, socioeconomic strata, and motivational stage on intervention effects will be explored.

\section{Qualitative analysis}

Qualitative focus group discussions (eight groups) will be protocolled by two researchers and audio-recorded. The aim of these focus groups discussions will be to assess the usability of the web-based intervention with subjective and objective PA monitoring (intervention group 2). Results of these focus groups will form the basis for improving interventions in the future, particularly for different user groups (e.g., females). Audiorecords will be transcribed and records will be compared and complemented by analyzing the protocols. Both, deductive and inductive methods will be used for analyzing the data based on Mayring [46].

\section{Ethics statement and consent}

This study was approved by the Ethics Committee of the Technical University of Chemnitz (TU Chemnitz), Faculty of Behavioural and Social Sciences, on July 14, 2015 number V-099-17-HS-CVR-PROMOTE-03072015. The study was registered at the German Clinical Trials Register on July 11, 2016 - number DRKS00010052. All study participants will be fully informed about the study and will be requested to give informed consent.

\section{Expected results}

We expect to find more pronounced increases in PA and the secondary outcomes in the two intervention arms (intervention groups 1 and 2) compared to the delayed intervention control group, as well as more pronounced intervention effects in persons in intervention group 2 compared to intervention group 1 . We base this assumption on previous trials conducted in the United States and other parts of Europe demonstrating significant increases in PA in persons participating in webbased interventions for PA promotion compared to control groups (e.g., [18, 21, 26, 47, 48]).

\section{Discussion}

This study will provide answers regarding acceptance and effectiveness of web-based interventions for the promotion of PA in persons aged 65-75 years living in Germany. Study findings will be interpreted alongside the results obtained in the other subprojects of the AEQUIPA project and network, hence contributing to the multi-disciplinary evidence regarding the relationship of PA and health and well-being among seniors. 


\section{Abbreviations}

ACSM: American College of Sports Medicine; AEQUIPA: Physical Activity and Health Equity: Primary Prevention for Healthy Ageing; AUDIT-C: Alcohol Use Disorders Identification Test Short Version; BMBF: German Federal Ministry of Education and Research; BRAHMS: Berlin Risk Appraisal and Health Motivation Study; CES-D: Centers for Epidemiologic Studies Depression Scale; CRA: Community Readiness Assessment; EFST: Elderly Fall Screening Test; GFFM: Geriatric Fear of Falling Measurement; HAPA: Health Action Process Approach; IPAQ: International Physical Activity Questionnaire; IPAQE: International Physical Activity Questionnaire Environmental module; NEO FFI: NEO Five Factor Inventory; PA: Physical activity; PSDQ: Physical selfdescription; RNGT: Random Number Generation Test; SF: Short-Form; SPPB: Short Physical Performance Battery; SWLS: Satisfaction with Life Scale VLMT: Verbal Learning and Memory Test; WHO: World Health Organization

\section{Acknowledgements}

The publication of this article was funded by the Open Access Fund of the Leibniz Association.

\section{Funding}

This study is funded by the German Federal Ministry of Education and Research (BMBF; project numbers 01EL1422A, 01EL1422C, 01EL1422E, 01EL1422F, 01EL1522I). The content of this article only reflects the authors' views and the funder is not liable for any use that may be made of the information contained therein

\section{Availability of data and materials}

After completion of the study, data can be shared with other researchers upon request but only in research collaborations with researchers of this study.

\section{Authors' contributions}

SM and CRP drafted the manuscript. SM, IB, CVR, ER, SL, JM, JS, MW, FK, MT, $T B, H Z$, and CRP have made substantial contributions to the conception and design of the study. All authors read, critically revised and approved the final manuscript.

\section{Competing interests}

The authors declare that they have no competing interests.

\section{Consent for publication}

Not applicable.

\section{Ethics approval and consent to participate}

This study was approved by the Ethics Committee of the Technical University of Chemnitz (TU Chemnitz), Faculty of Behavioural and Social Sciences, on July 14, 2015 - number V-099-17-HS-CVR-PROMOTE-03072015. The study was registered at the German Clinical Trials Register on July 11, 2016 - number DRKS00010052. All study participants will be fully informed about the study and will be requested to provide informed consent.

\section{Publisher's Note}

Springer Nature remains neutral with regard to jurisdictional claims in published maps and institutional affiliations.

\section{Author details}

${ }^{1}$ Leibniz Institute for Prevention Research and Epidemiology - BIPS, Achterstrasse 30, 28359 Bremen, Germany. ${ }^{2}$ Institute of Human Movement Science and Health, Technical University Chemnitz, Chemnitz, Germany. ${ }^{3}$ Jacobs University Bremen, Bremen, Germany. ${ }^{4}$ OFFIS - Institute for Information Technology, Oldenburg, Germany. ${ }^{5}$ Jade Hochschule, Oldenburg, Germany. ${ }^{6}$ Health Sciences Bremen, University of Bremen, Bremen, Germany.

Received: 3 April 2017 Accepted: 16 May 2017

Published online: 25 May 2017

\section{References}

1. Lee Y, Kim J, Han ES, Chae S, Ryu M, Ahn KH, et al. Changes in physical activity and cognitive decline in older adults living in the community. Age (Dordr). 2015;37:20
2. Hamer M, Lavoie KL, Bacon SL. Taking up physical activity in later life and healthy ageing: the English longitudinal study of ageing. Br J Sports Med. 2014;48:239-43

3. Warburton DE, Nicol CW, Bredin SS. Health benefits of physical activity: the evidence. CMAJ. 2006;174:801-9.

4. Witard OC, McGlory C, Hamilton DL, Phillips SM. Growing older with health and vitality: a nexus of physical activity, exercise and nutrition. Biogerontology. 2016;17:529-46.

5. World Health Organization. Global recommendations on physical activity for health. Geneva: World Health Organization; 2010. http://apps.who.int/iris/ bitstream/10665/44399/1/9789241599979_eng.pdf.

6. Nelson ME, Rejeski WJ, Blair SN, Duncan PW, Judge JO, King AC, et al. Physical activity and public health in older adults: recommendation from the American College of Sports Medicine and the American Heart Association. Med Sci Sports Exerc. 2007;39:1435-45.

7. Sun F, Norman IJ, While AE. Physical activity in older people: a systematic review. BMC Public Health. 2013:13:449.

8. Krug S, Jordan S, Mensink GB, Muters S, Finger J, Lampert T. Physical activity: results of the German health interview and examination survey for adults (DEGS1). Bundesgesundheitsblatt Gesundheitsforschung Gesundheitsschutz. 2013;56:765-71.

9. Bethancourt HJ, Rosenberg DE, Beatty T, Arterburn DE. Barriers to and facilitators of physical activity program use among older adults. Clin Med Res. 2014;12:10-20.

10. Noar SM, Benac CN, Harris MS. Does tailoring matter? Meta-analytic review of tailored print health behavior change interventions. Psychol Bull. 2007; 133:673-93.

11. Short CE, James EL, Plotnikoff RC, Girgis A. Efficacy of tailored-print interventions to promote physical activity: a systematic review of randomised trials. Int J Behav Nutr Phys Act. 2011:8:113.

12. Richards J, Hillsdon M, Thorogood M, Foster C. Face-to-face interventions for promoting physical activity. Cochrane Database Syst Rev. 2013: CD010392.

13. World Bank. The little book on information and communication technology. Washington: International Bank for Reconstruction and Development/The World Bank: 2013. https:/wwwitu.int/en/ITU-D/Statistics/Documents/ publications/ldb/LDB_ICT_2013.pdf.

14. Smith, A. Older adults and technolgy use. 2014. http://www.pewinternet. org/2014/04/03/older-adults-and-technology-use/. Accessed 12 Sept 2016.

15. Frees BK, Koch $W$. Internetnutzung. Frequenz und Vielfalt nehmen in allen Altersgruppen zu. Ergebnisse der ARD/ZDF-Onlinestudie 2015. Media Perspektiven. 2015;9:366-77.

16. eMarketer. Smartphones are all the rage in Germany. Over half of consumers in Germany now use a smartphone, compared with $41 \%$ in 2013. 2014. http://www.emarketer.com/Article/Smartphones-All-RageGermany/1010942. Accessed 12 Sept 2016.

17. World Health Organization. eHealth. 2016. http://www.who.int/topics/ ehealth/en/. Accessed 12 Sept 2016.

18. Irvine AB, Gelatt VA, Seeley JR, Macfarlane P, Gau JM. Web-based intervention to promote physical activity by sedentary older adults: randomized controlled trial. J Med Internet Res. 2013;15:e19.

19. Kim CJ, Kang DH. Utility of a web-based intervention for individuals with type 2 diabetes: the impact on physical activity levels and glycemic control. Comput Inform Nurs. 2006;24:337-45.

20. Peels DA, Bolman C, Golsteijn RH, de Vries H, Mudde AN, van Stralen MM, et al. Long-term efficacy of a printed or a web-based tailored physical activity intervention among older adults. Int J Behav Nutr Phys Act. 2013;10:104.

21. Wijsman CA, Westendorp RG, Verhagen EA, Catt M, Slagboom PE, de Craen AJ, et al. Effects of a web-based intervention on physical activity and metabolism in older adults: randomized controlled trial. J Med Internet Res. 2013;15:e233.

22. Broekhuizen K, Kroeze W, van Poppel MN, Oenema A, Brug J. A systematic review of randomized controlled trials on the effectiveness of computertailored physical activity and dietary behavior promotion programs: an update. Ann Behav Med. 2012:44:259-86.

23. Lustria ML, Noar SM, Cortese J, Van Stee SK, Glueckauf RL, Lee J. A metaanalysis of web-delivered tailored health behavior change interventions. J Health Commun. 2013;18:1039-69.

24. Neville LM, O'Hara B, Milat A. Computer-tailored physical activity behavior change interventions targeting adults: a systematic review. Int J Behav Nutr Phys Act. 2009;6:30. 
25. Storm V, Dorenkamper J, Reinwand DA, Wienert J, De Vries H, Lippke S. Effectiveness of a web-based computer-tailored multiple-lifestyle intervention for people interested in reducing their cardiovascular risk: a randomized controlled trial. J Med Internet Res. 2016;18:e78.

26. van Stralen MM, de Vries H, Mudde AN, Bolman C, Lechner L. The long-term efficacy of two computer-tailored physical activity interventions for older adults: main effects and mediators. Health Psychol. 2011;30:442-52.

27. Jordan S, Weiß M, Krug S, Mensink GB. Überblick über primärpräventive Maßnahmen zur Förderung von körperlicher Aktivität in Deutschland. Bundesgesundheitsblatt Gesundheitsforschung Gesundheitsschutz. 2012; 55:73-81.

28. Forberger S, Bammann K, Bauer J, Boll S, Bolte G, Brand T, et al. How to tackle key challenges in the promotion of physical activity among older adults (65+): the AEQUIPA network approach. IJERPH. 2017;14:379.

29. Brand T, Gansefort D, Rothgang H, Roseler S, Meyer J, Zeeb H. Promoting community readiness for physical activity among older adults in Germany - protocol of the ready to change intervention trial. BMC Public Health. 2016;16:99.

30. Rikli RE, Jones CJ. Functional fitness normative scores for communityresiding older adults, ages 60-94. J Aging Phys Act. 1999;7:162-81.

31. Guralnik JM, Simonsick EM, Ferrucci L, Glynn RJ, Berkman LF, Blazer DG, et al. A short physical performance battery assessing lower extremity function: association with self-reported disability and prediction of mortality and nursing home admission. J Gerontol. 1994;49:M85-94.

32. Kiphard EJ, Schilling F. Körper-Koordinationstest für Kinder. Weinheim: Beltz Test $\mathrm{GmbH} ; 1974$.

33. Morrows JR, Jackson AL, Disch JG, Mood DP. Measurement and evaluation. USA: Human Performance, Human Kinetics; 2000.

34. Bohannon RW, Schaubert KL. Test-retest reliability of grip-strength measures obtained over a 12-week interval from community-dwelling elders. J Hand Ther. 2005;18:426-7.

35. Cockrell JR, Folstein MF. Mini-mental state examination. Principles and practice of geriatric psychiatry. 2002:140-1.

36. Schelling D, Schächtele B. Materialien zur neuropsychologischen Diagnostik und Therapie. Pearson; 2009.

37. Bialystok E, Craik F, Luk G. Cognitive control and lexical access in younger and older bilinguals. J Exp Psychol Learn Mem Cogn. 2008;34:859-73.

38. Audiffren M, Tomporowski PD, Zagrodnik J. Acute aerobic exercise and information processing: modulation of executive control in a Random number Generation task. Acta Psychol. 2009;132:85-95.

39. Alberts JL, Hirsch JR, Koop MM, Schindler DD, Kana DE, Linder SM, et al. Using accelerometer and gyroscopic measures to quantify postural stability. J Athl Train. 2015;50:578-88.

40. Lippke S, Ziegelmann JP, Schwarzer R, Velicer WF. Validity of stage assessment in the adoption and maintenance of physical activity and fruit and vegetable consumption. Health Psychol. 2009;28:183-93.

41. Lippke S, Fleig L, Pomp S, Schwarzer R. Validity of a stage algorithm for physical activity in participants recruited from orthopedic and cardiac rehabilitation clinics. Rehabil Psychol. 2010;55:398-408.

42. Fleig L, Lippke S, Pomp S, Schwarzer R. Intervention effects of exercise selfregulation on physical exercise and eating fruits and vegetables: a longitudinal study in orthopedic and cardiac rehabilitation. Prev Med. 2011;53:182-7.

43. Pomp S, Fleig L, Schwarzer R, Lippke S. Effects of a self-regulation intervention on exercise are moderated by depressive symptoms: a quasiexperimental study. Int J Clin Health Psychol. 2013;13:1-8.

44. Michie S, Richardson M, Johnston M, Abraham C, Francis J, Hardeman W, et al. The behavior change technique taxonomy (v1) of 93 hierarchically clustered techniques: building an international consensus for the reporting of behavior change interventions. Ann Behav Med. 2013;46:81-95.

45. Cohen J. Statistical power analysis for the behavioral Sciences. Hillsdale, NY: Lawrence Erlbaum; 1988

46. Mayring PH. Qualitative Inhaltsanalyse. Grundlagen und Techniken. 7. Auflage edn. Deutscher Studien Verlag: Weinheim; 2000.

47. Mouton A, Cloes M. Efficacy of a web-based, center-based or combined physical activity intervention among older adults. Health Educ Res. 2015;30:422-35

48. King AC, Bickmore TW, Campero MI, Pruitt LA, Yin JL. Employing virtual advisors in preventive care for underserved communities: results from the COMPASS study. J Health Commun. 2013;18:1449-64.
49. Craig CL, Marshall AL, Sjostrom M, Bauman AE, Booth ML, Ainsworth BE, et al. International physical activity questionnaire: 12-country reliability and validity. Med Sci Sports Exerc. 2003;35:1381-95.

50. Stiller J, Würth S, Alfermann D. Die Messung des physischen Selbstkonzepts (PSK). Zeitschrift für Differentielle und Diagnostische Psychologie. 2004;25: 239-57.

51. Sallis JF, Kerr J, Carlson JA, Norman GJ, Saelens BE, Durant N, et al. Evaluating a brief self-report measure of neighborhood environments for physical activity research and surveillance: physical activity neighborhood environment scale (PANES). J Phys Act Health. 2010;7: 533-40.

52. Schinka JA, McBride A, Vanderploeg RD, Tennyson K, Borenstein AR, Mortimer JA. Florida cognitive activities scale: initial development and validation. J Int Neuropsychol Soc. 2005;11:108-16.

53. Jopp DS, Hertzog C. Assessing adult leisure activities: an extension of a selfreport activity questionnaire. Psychol Assess. 2010;22:108-20.

54. Bullinger M, Kirchberger I. Fragebogen zum Gesundheitszustand: SF-36. Handanweisung. Hogrefe, Verlag für Psychologie; 1998.

55. Hultsch DF, Hertzog C, Small BJ, Dixon RA. Use it or lose it: engaged lifestyle as a buffer of cognitive decline in aging? Psychol Aging. 1999;14:245-63.

56. Perloff LS, Fetzer BK. Self-other judgments and perceived vulnerability to victimization. J Pers Soc Psychol. 1986:50:502-10.

57. Cwikel JG, Fried AV, Biderman A, Galinsky D. Validation of a fall-risk screening test, the elderly fall screening test (EFST), for community-dwelling elderly. Disabil Rehabil. 1998;20:161-7.

58. Huang TT, Wang WS. Comparison of three established measures of fear of falling in community-dwelling older adults: psychometric testing. Int J Nurs Stud. 2009;46:1313-9.

59. Gallois KM, Buck C, Dreas JA, Hassel H, Zeeb H. Evaluation of an intervention using a self-regulatory counselling aid: pre- and post- intervention results of the OPTIMAHL 60plus study. Int J Public Health. 2013;58:449-58.

60. Saunders JB, Aasland OG, Babor TF, de la Fuente JR, Grant M. Development of the alcohol use Disorders Identification test (AUDIT): WHO collaborative project on early detection of persons with harmful alcohol consumption II. Addiction. 1993;88:791-804.

61. Renner B, Schwarzer R. Risk and health behaviors. Documentation of the scales of the research project: "risk Appraisal consequences in Korea" (RACK). Second ed; 2005.

62. Diener E, Emmons RA, Larsen RJ, Griffin S. The satisfaction with life scale. J Pers Assess. 1985;49:71-5.

63. Radloff LS. The CES-D scale: a self-report Depression scale for research in the general population. Appl Psychol Meas. 1977;1:385-401.

64. Borkenau P, Ostendorf F. NEO-Fünf-Faktoren Inventar: (NEO-FFI). Nach Costa und McCrae. Hogrefe, Verlag für Psychologie; 1993.

65. Neyer FJ, Felber J, Gebhardt C. Entwicklung und Validierung einer Kurzskala zur Erfassung von Technikbereitschaft. Diagnostica. 2012;58:87-99.

\section{Submit your next manuscript to BioMed Central and we will help you at every step:}

- We accept pre-submission inquiries

- Our selector tool helps you to find the most relevant journal

- We provide round the clock customer support

- Convenient online submission

- Thorough peer review

- Inclusion in PubMed and all major indexing services

- Maximum visibility for your research

Submit your manuscript at www.biomedcentral.com/submit 